\title{
Application of proteomics to identify the target molecules involved in Lonicera japonica-induced photokilling in human lung cancer $\mathrm{CH} 27$ cells
}

\author{
Jung C Liao ${ }^{1 \dagger}$, Wen T Chang ${ }^{2 \dagger}$, Yu H Lan ${ }^{1}$, Mann J Hour ${ }^{1}$ and Hong Z Lee
}

\begin{abstract}
Background: The Lonicera japonica has been used as natural and healthy drink for its anti-inflammatory effect and pleasant odor in China and Taiwan.

Methods: 2D electrophoresis was used to analyze the proteins involved in photoactivated Lonicera japonicainduced $\mathrm{CH} 27$ cell apoptosis. The fluorescent dyes MitoTracker Red CMXRos, calcein AM and JC-1 were used to elucidate mitochondrial function. The protein expression was performed by Western blotting. Fluorescent image of endoplasmic reticulum was accomplished by using ER-Tracker Green. This study used fluorescent dye $\mathrm{CM}^{-\mathrm{H}_{2} \mathrm{DCFDA}}$ to detect intracellular generation of reactive oxygen species.

Results: The identified proteins can be classified into three major groups, which include proteins involved in mitochondrial function, cytoskeleton-related proteins and proteins associated with endoplasmic reticulum (ER) stress. Photoactivated Lonicera japonica caused a significant effect on the mitochondrial function and ER stress in $\mathrm{CH} 27$ cells. The reactive oxygen species producing was found to be involved in photoactivated Lonicera japonicainduced $\mathrm{CH} 27$ cell apoptosis.

Conclusion: Mitochondria and endoplasmic reticulum are the integral targets in photoactivated Lonicera japonicainduced $\mathrm{CH} 27$ cell apoptosis. We also demonstrated that ethyl acetate fraction of Lonicera japonica extracts caused photocytotoxicity in a dose-dependent manner in $\mathrm{CH} 27$ cells. This could explain the fact that the ethyl acetate fraction of Lonicera japonica extracts may contain compounds which exhibit the photosensitizing activity in $\mathrm{CH} 27$ cells.
\end{abstract}

Keywords: Lonicera japonica, Human lung squamous carcinoma CH27 cells, Photocytotoxicity, 2D electrophoresis, Mitochondrial chaperones, Endoplasmic reticulum chaperones

\section{Background}

The Lonicera japonica flower is called Jin Yin Hua in China and Taiwan. Jin Yin Hua is often used in traditional Chinese medicine to treat excess heat conditions such as fevers, skin rashes and sore throat. Therefore, Jin Yin Hua has been used as natural and healthy drink for its anti-inflammatory effect and pleasant odor. Recently, the mechanisms of Lonicera japonica in anti-inflammatory and anti-tumor activity have been reported [1,2]. Lonicera japonica extracts has been found to be an effective non-steroidal anti-

\footnotetext{
* Correspondence: hong@mail.cmu.edu.tw

${ }^{\dagger}$ Equal contributors

'School of Pharmacy, China Medical University, Taichung, Taiwan

Full list of author information is available at the end of the article
}

inflammatory drug because it shows preferential inhibition toward cyclooxygenase- 2 activity and protein expression [2]. Park et al. [1] demonstrated that the polyphenolic extract isolated from Lonicera japonica triggered HepG2 cell death through inhibition of PI3K/Akt and activation of mitogen-activated protein kinases (MAPKs). Photodynamic therapy (PDT) which uses the activation of tumorlocalizing photosensitizing agents by visible light is an effective therapy for local malignant tumors. In our previous study, Lonicera japonica was found to exhibit a significant photocytotoxicity in human lung squamous carcinoma $\mathrm{CH} 27$ cells [3]. We also demonstrated that the promotion of the cytoskeleton-related signaling cascade following rottlerin reduced photoactivated Lonicera japonica-induced 
$\mathrm{CH} 27$ cell death [4]. However, the molecular mechanisms underlying the biological effects of photoactivated Lonicera japonica still remain unknown. Proteomics is now generally accepted as a method to analyze total protein expression and elucidate cellular processes at the molecular level $[5,6]$. In this study, proteomics was used to identify the marker proteins that are involved in photoactivated Lonicera japonica-induced $\mathrm{CH} 27$ cell apoptosis.

Many reports emphasize that heat shock proteins (HSPs), which are synthesized by cells in response to various stress conditions, have a complex role in antiapoptosis. In general, molecular chaperones can be found in both the cytoplasm and organelles, such as the nucleus, mitochondria and endoplasmic reticulum (ER) in cells. It has been reported that overexpression of HSP60 is sufficient to prevent apoptosis by protecting mitochondrial function in cardiac myocytes [7]. HSP70 and HSP27 inhibit apoptosis through prevention recruitment of procaspase- 9 from the apaf-1 apoptosome and inhibition cytochrome $c$-dependent activation of procaspase-9 respectively $[8,9]$. A number of different models have been proposed to explain that the ER serves as a critical apoptotic control point and has a complex role in apoptosis [10-12]. Endoplasmic reticulum stress, which is induced by the accumulation of misfolded proteins in the endoplasmic reticulum, can initiate cell death under pathological conditions [12]. When cells accumulate ER stresses, ER chaperones can be induced to alleviate protein aggregation and activate the proteosome machinery to degrade misfolded proteins. Furthermore, Feng et al. [10] suggested that induction of ER stress protects gastric cancer cells against apoptosis induced by cisplatin and doxorubicin through activation of p38 MAPK.

Free radicals are a family of molecules, which modulate several important physiological functions including proliferation and apoptosis. Many studies reported that reactive oxygen species (ROS) participated in apoptosis through inducing mitochondrial dysfunction $[11,13]$. Furthermore, reactive oxygen species production is believed to play a key role in photosensitizer-induced photocytotoxicity. Many investigators have suggested that PDT involves activation of a photosensitizer, which induced singlet oxygen and other reactive oxygen species formation after exposure to light, causing cancer cells to undergo apoptosis or necrosis [14-17].

According to our study of 2D electrophoresis, molecular chaperone proteins involved in mitochondrial function and ER stress, and cytoskeleton-related proteins were participated in photoactivated Lonicera japonicainduced $\mathrm{CH} 27$ cell death. Molecular chaperone expression, mitochondrial function and endoplasmic reticulum stress served as important apoptotic control point in photoactivated Lonicera japonica-induced apoptosis in this study.

\section{Methods \\ Materials}

Antipain, aprotinin, dithiothreitol (DTT), ethyleneglycolbis-( $\beta$-aminoethyl ether)-N,N,N',N'-tetraacetic acid (EGTA), leupeptin, pepstatin, phenylmethylsulfonyl fluoride (PMSF) and Tris were purchased from Sigma Chemical Company (St. Louis, MO, USA). Antibodies to various proteins were obtained from the following sources: $\beta$-Actin was from Sigma Chemical Company. PDI and HSP70 were purchased from BD Biosciences (San Diego, CA, USA). HSP60 was purchased from Calbiochem (San Diego, CA, USA). 150 kDa Oxygenregulated protein (ORP150) was purchased from IBL (Japan). Caspase-4 was purchased from Abcam (Cambridge, MA, USA). MitoTracker Red CMXRos and ER-Tracker Green reagent were from Molecular Probes (Eugene, OR, USA).

\section{Preparation of Lonicera japonica}

The botanical origin of Lonicera japonica was identified by Dr. Chao-Lin Kuo (School of Chinese Pharmaceutical Sciences and Chinese Medicine Resources, China Medical University, Taichung, Taiwan). The voucher specimen (Lonicera japonica: CMU LJ 0614) was deposited in School of Chinese Pharmaceutical Sciences and Chinese Medicine Resources, China Medical University, Taichung, Taiwan. The air-dried plants of Lonicera japonica (200 g) were soaked three times with $1 \mathrm{~L}$ of $95 \%$ ethanol at room temperature for 3 days. The extracts were filtered. The filtrates were collected and then concentrated under reduced pressure at $40^{\circ} \mathrm{C}$. The yield of dry extract of Lonicera japonica was about $11 \%$.

\section{Cell culture}

$\mathrm{CH} 27$ cells were grown in monolayer culture in Dulbecco's modified Eagle's medium (DMEM; Life Technologies, Rockville, MD, USA) containing 5\% FBS (HyClone, Logan, UT, USA), $100 \mathrm{U} / \mathrm{ml}$ penicillin, $100 \mu \mathrm{g} / \mathrm{ml}$ streptomycin (Gibco BRL, Rockville, MD, USA) and $2 \mathrm{mM}$ glutamine (Merck, Darmstadt, Germany) at $37^{\circ} \mathrm{C}$ in a humidified atmosphere comprised of $95 \%$ air and $5 \% \mathrm{CO}_{2}$. When $\mathrm{CH} 27$ cells were treated with Lonicera japonica, the culture medium containing 1\% FBS was used. All data presented in this study are from at least 3 independent experiments.

\section{Light source}

The irradiation source was a set of fluorescent lamp $(2 \times 20 \mathrm{~W}$; China Electric MFG Corporation, Taiwan, R. O.C.) located in a made-to-measure box. The wavelength of the fluorescence lamp was in the range of 400$700 \mathrm{~nm}$. The intensity of light was measured as Lux and 
Lux was converted to light dose $\left(\mathrm{J} / \mathrm{cm}^{2}\right)$. The cells were irradiated at $40 \mathrm{~W}$ for $30 \mathrm{~min}$, corresponding to $0.8 \mathrm{~J} / \mathrm{cm}^{2}$ light dose.

\section{Protein preparation}

Cells were seeded at a density of $1.7 \times 10^{6}$ cells onto 10 $\mathrm{cm}$ dish $48 \mathrm{~h}$ before being treated with drugs. $\mathrm{CH} 27$ cells were incubated with $0.1 \%$ dimethylsulfoxide (DMSO) or $100 \mu \mathrm{g} / \mathrm{ml}$ Lonicera japonica extracts and then irradiated with $0.8 \mathrm{~J} / \mathrm{cm}^{2}$ fluence dose. After irradiation, adherent and floating cells were collected and washed twice in ice-cold phosphate-buffered saline (PBS). Cell pellets were resuspended in cell lysis buffer $(50 \mathrm{mM}$ Tris- $\mathrm{HCl}$, $\mathrm{pH} 7.5,150 \mathrm{mM}$ sodium chloride, 1\% Nonidet P-40, $0.25 \%$ sodiumdeoxycholate, $1 \mathrm{mM}$ EGTA, $1 \mathrm{mM}$ DTT, $1 \mathrm{mM}$ PMSF, $1 \mathrm{mM}$ sodium orthovanadate, $1 \mathrm{mM}$ sodium fluoride, $5 \mu \mathrm{g} / \mathrm{ml}$ aprotinin, $5 \mu \mathrm{g} / \mathrm{ml}$ leupeptin and $5 \mu \mathrm{g} / \mathrm{ml}$ antipain) for $30 \mathrm{~min}$ at $4^{\circ} \mathrm{C}$. Lysates were clarified by centrifugation at $13,000 \mathrm{rpm}$ for $30 \mathrm{~min}$ at $4^{\circ} \mathrm{C}$. The resulting supernatant was collected, aliquoted $(150 \mu \mathrm{g} /$ tube for 2D electrophoresis and $50 \mu \mathrm{g} /$ tube for Western blot) and stored at $-80^{\circ} \mathrm{C}$ until assay. The protein concentrations were estimated with the Bradford method.

\section{Two-dimensional gel electrophoresis}

The proteins $(150 \mu \mathrm{g})$ were dissolved in a rehydration buffer (9.8 M urea, 0.5\% CHAPS, $10 \mathrm{mM}$ DTT, 0.2\% Biolytes and a trace of bromophenol blue) to a final volume of $125 \mu \mathrm{l}$. The samples were added to the 7-cm IPG strips (pH 4-7, linear, Readystrip; BioRad, Hercules, CA), which were rehydrated for $12 \mathrm{~h}$. After rehydration, the strips were focused for $60,000 \mathrm{Vh}$, starting at $250 \mathrm{~V}$ and gradually raising the voltage to $10,000 \mathrm{~V}$. Once the IEF was completed, the strips were equilibrated in $6 \mathrm{M}$ urea containing $2 \%$ SDS, $0.375 \mathrm{M}$ Tris (pH 8.8), 20\% glycerol and $130 \mathrm{mM}$ DTT. The 2D electrophoresis was performed using $12 \%$ sodium dodecyl sulfate-polyacrylamide gel electrophoresis (SDS-PAGE).

\section{Silver staining of proteins}

Gels were fixed in 50\% methanol (v/v) and 12\% acetic acid $(\mathrm{v} / \mathrm{v})$ for $2 \mathrm{~h}$, and then washed 3 times in 50\% ethanol $(\mathrm{v} / \mathrm{v})$. The duration of each wash was $20 \mathrm{~min}$. Gels were then incubated in a $0.02 \%$ sodium thiosulfate solution (w/v) for $1 \mathrm{~min}$, followed by four 1 -min washes in water. Gels were then placed in a solution composed of $0.2 \%$ silver nitrate $(\mathrm{w} / \mathrm{v})$ and $0.075 \%(\mathrm{v} / \mathrm{v})$ formaldehyde for a period of $20 \mathrm{~min}$, followed by three 1-min washes in water. Gels were then developed in a $6 \%$ sodium carbonate $(\mathrm{w} / \mathrm{v}), 0.005 \%$ formaldehyde $(\mathrm{v} / \mathrm{v})$ and $0.004 \%$ sodium thiosulfate $(\mathrm{w} / \mathrm{v})$ solution until the protein spots were visualized. A $1 \%$ acetic acid solution was added to stop the staining reactions.

\section{NanoLC-MS/MS analysis and database searches}

NanoLC-MS/MS analysis was performed on an integrated nanoLC-MS/MS system (QSTAR XL) comprising a LC Packings NanoLC system with an autosampler and a QSTAR XL Q-Tof mass spectrometer (Applied Biosystems, Foster City, CA) fitted with nanoLC sprayer. Mass analysis was carried out according to the Analyst QS software (Applied Biosystems). The proteins were identified by searching in SWISS-PROT and NCBI database using the Mascot program with the following parameters: peptide mass tolerance, $50 \mathrm{ppm}$; MS/MS ion mass tolerance, $0.25 \mathrm{Da}$; and allow up to one missed cleavage. Only significant hits as defined by Mascot probability analysis will be considered initially.

\section{Measurement of mitochondrial function}

$\mathrm{CH} 27$ cells were incubated with $0.1 \%$ DMSO or Lonicera japonica for $4 \mathrm{~h}$ and then irradiated with $0.8 \mathrm{~J} / \mathrm{cm}^{2}$ light dose. Mitochondrial activity, the opening of mitochondrial permeability transition (MPT) pore and mitochondrial membrane potential (MMP) were measured as previously described $[4,11]$. To detect mitochondrial activity, cells were incubated for $30 \mathrm{~min}$ at $37^{\circ} \mathrm{C}$ with $100 \mathrm{nM}$ MitoTracker Red CMXRos and observed by fluorescent microscope (Olympus IX 70). To measure the opening of MPT pore, the fluorescence intensity of calcein was measured with FACSCanto flow cytometer (excitation, $488 \mathrm{~nm}$; emission, $530 \mathrm{~nm}$ ) and analysed using ModFit LT 3.0 Software (Verity Software House, Topsham, ME, USA). MMP was determined by flow cytometry analysis of JC-1 (5, $5^{\prime}, 6,6^{\prime}$-tetrachloro- $1,1^{\prime}, 3,3^{\prime}$ tetraethylbenzimidazolocarbocyanine iodide)-stained cells.

\section{Western blot analysis}

Samples were separated by various indicated concentrations of SDS-PAGE. The SDS-separated proteins were equilibrated in transfer buffer $(50 \mathrm{mM}$ Tris- $\mathrm{HCl}, \mathrm{pH} 9.0-$ 9.4, $40 \mathrm{mM}$ glycine, $0.375 \%$ SDS and $20 \%$ methanol) and electrotransferred to Immobilon-P transfer membranes (Millipore Corporation, Bedford, MA). The blot was blocked with a solution containing 5\% nonfat dry milk in TBST for $1 \mathrm{~h}$, washed and incubated with antibodies to $\beta$-actin (1:5000 [Sigma], the detection of $\beta$-actin was used as an internal control in the data of Western blotting analysis), ORP150 (1:100), PDI (1:250), HSP60 (1:7000), HSP70 (1:1000) and caspase-4 (1:12,000). Secondary antibody consisted of a 1:20,000 dilution of horseradish peroxidase (HRP)-conjugated goat antimouse IgG (for $\beta$-actin, ORP150, PDI, HSP60 and HSP70) and HRP-conjugated goat anti-rabbit IgG (for caspase-4). The enhanced chemiluminescent (NEN Life Science Products, Boston, MA) detection system was used for immunoblot protein detection. 


\section{Fluorescent imaging of endoplasmic reticulum (ER)}

Fluorescent imaging of endoplasmic reticulum was accomplished using ER-Tracker Green (glibenclamideBODIPY FL) and used as directed by the manufacturer. $\mathrm{CH} 27$ cells were seeded onto 12-well plate $48 \mathrm{~h}$ before being treated with Lonicera japonica and light. After irradiation, cells were incubated for $30 \mathrm{~min}$ at $37^{\circ} \mathrm{C}$ with $1 \mu \mathrm{M}$ of ER-Tracker. The cells were then washed with PBS and examined by fluorescence microscopy (300x).

\section{Measurement of reactive oxygen species production}

This study used 5-(and-6)-chloromethyl-20,70-dichlorodihydrofluorescein diacetate $\left(\mathrm{CM}-\mathrm{H}_{2} \mathrm{DCFDA}\right.$, Molecular Probes) to detect intracellular generation of reactive oxygen species. $\mathrm{CH} 27$ cells were loaded with $5 \mu \mathrm{M} \mathrm{CM}-\mathrm{H}$ ${ }_{2}$ DCFDA for $40 \mathrm{~min}$ in the dark. During loading, the acetate groups on $\mathrm{CM}-\mathrm{H}_{2} \mathrm{DCFDA}$ were removed by intracellular esterase, trapping the probe inside the cells. Cells loaded with $\mathrm{CM}-\mathrm{H}_{2} \mathrm{DCF}$ were treated with various indicated concentrations of Lonicera japonica and then irradiated with $0.8 \mathrm{~J} / \mathrm{cm}^{2}$ light dose. After irradiation, production of reactive oxygen species can be measured by changes in fluorescence due to intracellular production of CM-DCF caused by oxidation of $\mathrm{CM}-\mathrm{H}_{2} \mathrm{DCF}$. CM-DCF fluorescence was measured using a fluorometer (Thermo Scientific Fluoroskan Ascent FL; Helsinki, Finland) at an excitation wavelength of $480 \mathrm{~nm}$ and an emission wavelength of $520 \mathrm{~nm}$.

\section{Fractionation of the Lonicera japonica extracts}

The alcoholic extracts of Lonicera japonica was suspended in water and partitioned successively with ethyl acetate (EtOAc) and $n$-butanol $(\mathrm{BuOH})$. Each extract was evaporated to dryness under reduced pressure to yield water, ethyl acetate and $n$-butanol fractions.

\section{Mitochondrial Reductase activity}

Cells were seeded at a density of $1 \times 10^{5}$ cells per well onto 12-well plate $48 \mathrm{~h}$ before being treated with drugs. The cells were incubated with $0.1 \%$ DMSO or partitioned fractions of Lonicera japonica extracts and then irradiated with the light dose of $0.8 \mathrm{~J} / \mathrm{cm}^{2}$. After irradiation, the cells were washed with PBS. Cellular mitochondrial reductase activity of live $\mathrm{CH} 27$ cells was determined by measuring the reduction of 3-(4,5dimethylthiazol-2-yl)-2,5-diphenyltetrazolium bromide $(\mathrm{MTT})$. Cells were incubated with MTT $\left(2.4 \times 10^{-4} \mathrm{M}\right)$ for $1 \mathrm{~h}$ at $37^{\circ} \mathrm{C}$. After solubilization in dimethylsulfoxide, absorbance was measured at $550 \mathrm{~nm}$.

\section{Statistical analysis}

All experiments were carried out at least three independent experiments. Each sample was tested in triplicate. Standard statistical methods based on Student's $t$ test and regression analysis were used. The results are expressed as percentage \pm S.D. of control.

\section{Results \\ Identification of differentially expressed proteins by 2D gel}

The major purpose of this study was to investigate the change in protein level during Lonicera japonica-induced photocytotoxicity of $\mathrm{CH} 27$ cells. Therefore, this study examine the difference between control cell-loaded and the photoactivated Lonicera japonica-treated cell loaded gels in the $\mathrm{pH}$ range of 4.75-6.5, using a 4-7 $\mathrm{pH}$ range IPG strip in the first dimension. Therefore, those proteins with $\mathrm{pI}$ value less than 4 and more than 7 would be missed. The control cells were treated with $0.1 \%$ DMSO and then irradiated with $0.8 \mathrm{~J} / \mathrm{cm}^{2}$ fluence dose. In this study, light alone did not affect cell survival and protein expression (data not shown). After being incubated with $100 \mu \mathrm{g} / \mathrm{ml}$ Lonicera japonica for $4 \mathrm{~h}$ and $0.8 \mathrm{~J} / \mathrm{cm}^{2}$ irradiation, many protein spots were found varying in intensity between the control cell-loaded and the photoactivated Lonicera japonicatreated cell-loaded gels (Figure 1). Photoactivated Lonicera japonica triggered significant decreases in the protein expression of spots D1-D8 (Figure 1). In Lonicera japonicaphotosensitized cells, the protein expression of spots \#1-\#8 is more intense than those in the control cells (Figure 1). These altered protein spots were identified by mass spectrometry and Mascot search. As shown in Table 1, the identified proteins can be classified into three major groups, which include proteins involved in mitochondrial function (DJ-1, ATP synthase, heat shock protein 70 and chaperonin, also known as heat shock protein 60), cytoskeleton-related proteins (heat shock protein 27, tropomyosin and actin cytoplasmic 1) and proteins associated with ER stress (protein disulfide isomerase). It is interesting to note that four spot families in the horizontal direction of the $2 \mathrm{D}$ gel were found to markedly change after treatment with $100 \mu \mathrm{g} / \mathrm{ml}$ Lonicera japonica for $4 \mathrm{~h}$ and $0.8 \mathrm{~J} / \mathrm{cm}^{2}$ light dose (Figure 1). These altered protein spot families were identified as protein disulfide isomerase, heat shock protein 70, chaperonin and actin cytoplasmic 1 . These protein spot families are identical in molecular weight but different in $\mathrm{pI}$ values. We found six $73-\mathrm{kDa}$ heat shock protein 70 with pI values of 5.23-5.60 (Figure 1; arrow S1), four 61-kDa chaperonin with pI values of 5.15-5.34 (Figure 1; arrow S2), five 57-kDa protein disulfide isomerase with pI values of 5.54-5.88 (Figure 1; arrow S3) and eight $42-\mathrm{kDa}$ actin cytoplasmic 1 proteins with pI values of 4.97-5.43 (Figure 1; arrow S4) in the horizontal direction of the $2 \mathrm{D}$ gel. It has been indicated that the single spots of the complex pattern were probably due to post-translational modifications of one particular protein. Our results suggested that photoactivated Lonicera japonica-induced changes in protein expression of many 


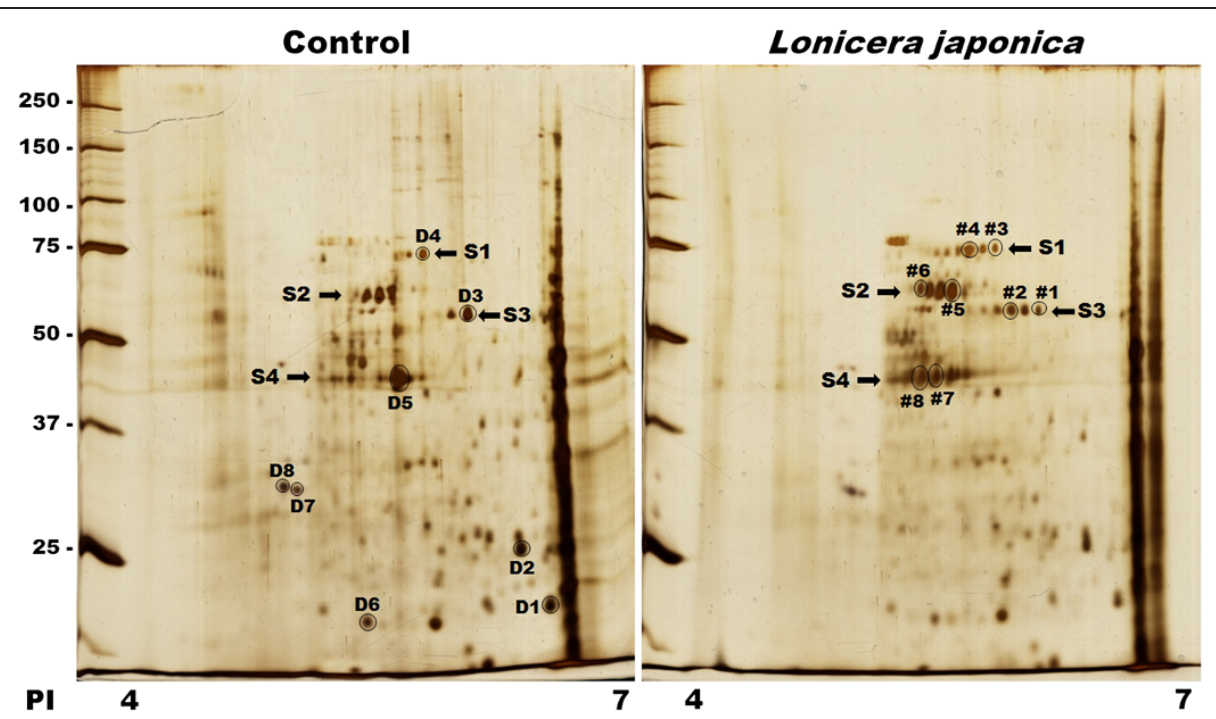

Figure 1 Two-dimensional electrophoresis maps of control and Lonicera japonica-photosensitized $\mathrm{CH} 27$ cells. Cells were incubated with $0.1 \%$ DMSO or $100 \mu \mathrm{g} / \mathrm{ml}$ Lonicera japonica extracts for $4 \mathrm{~h}$ and then irradiated with $0.8 \mathrm{~J} / \mathrm{cm}^{2}$ fluence dose. Proteins were separated on a pH 4-7 IPG-strip (7 cm) in the first dimension and on a 12\% SDS-polyacrylamide gel in the second dimension. Staining of the protein spots was accomplished by silver nitrate. Results are representative of three independent experiments.

proteins include the pattern of their post-translational modifications in $\mathrm{CH} 27$ cells.

\section{Effects of photoactivated Lonicera japonica on mitochondrial function in $\mathrm{CH} 27$ cells}

In the results of $2 \mathrm{D}$ electrophoresis, photoactivated Lonicera japonica-treated samples had a significant change in the expression of DJ-1, ATP synthase, heat shock protein 70 and chaperonin which are involved in mitochondrial function. To examine whether the activity of mitochondria was injured by photoactivated Lonicera japonica in $\mathrm{CH} 27$ cells, MitoTracker Red CMXRos dye was used in this study. A bright red fluorescence was observed on numerous and dot-like structures in controltreated cells' cytoplasm (Figure 2A). In photoactivated Lonicera japonica-treated cells, the red fluorescence was significantly decreased in a dose-dependent manner (Figure 2A). This result suggested that the capability for MitoTracker Red CMXRos uptake by mitochondria in control cells is higher compared to those in Lonicera japonica photosensitized cells. To confirm the possible role of MPT pore in the process of Lonicera japonica-induced photocytoxicity, we measured the opening of mitochondrial permeability transition (MPT) pore in intact cells by flow cytometry. As shown in Figure 2B, treatment with $100 \mu \mathrm{g} / \mathrm{ml}$ Lonicera japonica extracts for $4 \mathrm{~h}$ and then $0.8 \mathrm{~J} / \mathrm{cm}^{2}$ fluence dose resulted in a decrease in calcein fluorescent intensity because of the opening of MPT pores. However, treatment with $100 \mu \mathrm{g} / \mathrm{ml}$ Lonicera japonica extracts for $4 \mathrm{~h}$ had no effect on the calcein fluorescent intensity of $\mathrm{CH} 27$ cells in the dark (Figure 2B). Because the opening of MPT pore is accompanied by a decrease in mitochondrial membrane potential (MMP), this study examined the photodynamic effect of Lonicera japonica on MMP in $\mathrm{CH} 27$ cells. After cells were treated with Lonicera japonica extracts and irradiation, a remarkable attenuation of MMP occurred compared to the control cells or the cells treated with $100 \mu \mathrm{g} / \mathrm{ml}$ Lonicera japonica extracts in the dark (Figure 2C). These results clearly demonstrated that mitochondrial function is severely impaired by photoactivated Lonicera japonica in $\mathrm{CH} 27$ cells. To further elucidate whether the protein expression of HSP60 (chaperonin) and HSP70 is involved in photoactivated Lonicera japonica-induced $\mathrm{CH} 27$ cell apoptosis, this study examined the regulation of HSP60 and HSP70 levels by Western blotting analysis. Exposure of $\mathrm{CH} 27$ cells to $100 \mu \mathrm{g} / \mathrm{ml}$ Lonicera japonica for 2 or $4 \mathrm{~h}$ and $0.8 \mathrm{~J} / \mathrm{cm}^{2}$ irradiation resulted in increases in protein level of HSP60 (Figure 3). However, photoactivated Lonicera japonica had no effect on the protein expression of HSP70 (Figure 3).

\section{ER stress was involved in photoactivated Lonicera japonica-induced $\mathrm{CH} 27$ cell death}

According to the results of 2D elecrtophoresis, photoactivated Lonicera japonica induced a significant change in the protein expression of protein disulfide isomerase (PDI). PDI, a molecular chaperone in the endoplasmic reticulum (ER), catalyzes the formation and breakage of disulfide bonds between cysteine residues within proteins as they fold. To further elucidate whether ER is a target in the photoactivated Lonicera japonica $(100 \mu \mathrm{g} / \mathrm{ml})$-induced $\mathrm{CH} 27$ cell death, the 
Table $1 \mathrm{MS} / \mathrm{MS}$ analysis and characteristics of the analyzed spots

\begin{tabular}{|c|c|c|c|c|c|c|c|}
\hline Spot & Protein & Accession no. & $\begin{array}{c}\text { Calculated } \\
\text { pl }\end{array}$ & $\begin{array}{l}\text { Theoretical pl/Mw } \\
\text { (Da) }\end{array}$ & Score & $\begin{array}{c}\text { Sequence } \\
\text { coverage (\%) }\end{array}$ & $\begin{array}{l}\text { Changed fold } \\
{\text { (\% control })^{1}}^{1}\end{array}$ \\
\hline D1 & DJ-1 protein & NP_009193 & 6.33 & $6.32 / 19891.05$ & 88 & 25 & $40 \pm 4$ \\
\hline D2 & Heat shock protein 27 & AAA62175 & 6.16 & $5.98 / 22782.52$ & 273 & 43 & $46 \pm 5$ \\
\hline D3 & Protein disulfide isomerase & CAA89996 & 5.85 & $5.98 / 56782.39$ & 766 & 40 & $48 \pm 9$ \\
\hline D4 & Heat shock 70 kDa protein 9 & AAH00478 & 5.59 & $5.87 / 73680.50$ & 508 & 28 & $49 \pm 7$ \\
\hline D5 & Actin, cytoplasmic 1 & NP_001092 & 5.42 & $5.29 / 41736.73$ & 896 & 43 & $41 \pm 5$ \\
\hline D6 & ATP synthase & NP_006347 & 5.21 & $5.21 / 18491.21$ & 147 & 34 & $48 \pm 3$ \\
\hline D7 & Tropomyosin 3 isoform 2 & NP_705935 & 4.81 & $4.68 / 32818.79$ & 283 & 29 & $45 \pm 11$ \\
\hline D8 & Tropomyosin 3 isoform 4 & NP_001036816 & 4.73 & $4.73 / 28870.36$ & 283 & 29 & $79 \pm 5$ \\
\hline$\# 1$ & Protein disulfide isomerase & CAA89996 & 5.88 & $5.98 / 56782.39$ & 423 & 32 & $383 \pm 26$ \\
\hline$\# 2$ & Protein disulfide isomerase & CAA89996 & 5.70 & $5.98 / 56782.39$ & 494 & 32 & $143 \pm 21$ \\
\hline$\# 3$ & $\begin{array}{l}\text { Heat shock } 70 \mathrm{kDa} \text { protein } 9 \mathrm{~B} \text { precursor } \\
\text { variant }\end{array}$ & BAD96478 & 5.60 & $5.87 / 73680.50$ & 405 & 25 & $1594 \pm 115$ \\
\hline$\# 4$ & Heat shock 70 kDa protein 8 isoform 1 & NP_006588 & 5.43 & $5.61 / 53499.58$ & 540 & 28 & $366 \pm 62$ \\
\hline$\# 5$ & Chaperonin & NP_002147 & 5.34 & $5.70 / 61054.64$ & 760 & 46 & $145 \pm 25$ \\
\hline \#6 & Chaperonin & NP_002147 & 5.15 & $5.70 / 61054.64$ & 600 & 31 & $386 \pm 51$ \\
\hline \#7 & Actin, cytoplasmic 1 & NP_001092 & 5.25 & $5.29 / 41736.73$ & 336 & 37 & $266 \pm 10$ \\
\hline$\# 8$ & Actin, cytoplasmic 1 & NP_001092 & 5.15 & $5.29 / 41736.73$ & 262 & 39 & $376 \pm 43$ \\
\hline
\end{tabular}

${ }^{1}$ The expression of protein spots was quantified by AlphaEase image software. All protein changed folds are expressed as the mean percentage of the relative control \pm S.D. from three independent experiments.

protein expression of ER-related molecular chaperones, such as PDI, $150 \mathrm{kDa}$ oxygen-regulated protein (ORP150) and caspase-4, was examined by Western blotting analysis in this study. Exposure of $\mathrm{CH} 27$ cells to $100 \mu \mathrm{g} / \mathrm{ml}$ Lonicera japonica for 1,2 or $4 \mathrm{~h}$ and $0.8 \mathrm{~J} /$ $\mathrm{cm}^{2}$ irradiation resulted in increases in protein level of ORP150 and PDI, but caspase-4 level decreased after $2 \mathrm{~h}$ (Figure 3). Since ORP150 and PDI are the markers of ER stress, we further investigated the role of ER stress in the photoactivated Lonicera japonica-induced apoptosis. In order to demonstrate the role that ER stress plays in the photoactivated Lonicera japonica-induced apoptosis, $\mathrm{CH} 27$ cells were incubated with an endoplasmic reticulum marker, ER-Tracker ${ }^{\text {Tw }}$ Green reagent. In control cells, the ER-tracker fluorescence is mostly found in the cytoplasm, consistent with endoplasmic reticulum localization (Figure 4A). As shown in Figure 4, cells exhibited a heterogeneous distribution of the fluorescence after treatment with 100 or $150 \mu \mathrm{g} / \mathrm{ml}$ Lonicera japonica for $4 \mathrm{~h}$ and $0.8 \mathrm{~J} / \mathrm{cm}^{2}$ irradiation. Based on the above data, we demonstrated that ER stress was involved in the photoactivated Lonicera japonica-induced $\mathrm{CH} 27$ cell apoptosis.

Photoactivated Lonicera japonica induced reactive oxygen species (ROS) generation in $\mathrm{CH} 27$ cells

It is well-known that reactive oxygen species participate in apoptosis by inducing the mitochondrial dysfunction and ER stress. In addition, a variety of ROS is produced including singlet molecular oxygen $\left({ }^{1} \mathrm{O}_{2}\right.$, produced via type II mechanism) and superoxide anions (type I mechanism) by photosensitizer during the photodynamic process. In order to demonstrate the role that ROS plays in Lonicera japonica-induced photocytotoxicity, intracellular ROS generation was examined by using an oxidant sensitive fluorescent probe, $\mathrm{CM}-\mathrm{H}_{2}$ DCFDA. The results showed that treatment with $100 \mu \mathrm{g} / \mathrm{ml}$ Lonicera japonica for $2 \mathrm{~h}$ and $0.8 \mathrm{~J} / \mathrm{cm}^{2}$ light dose resulted in significant increases in the intensity of the DCF signal as compared with those in the control (Figure 5). In this study, it was confirmed whether the production of ROS was caused only by irradiation. The amount of ROS induced by $100 \mu \mathrm{g} / \mathrm{ml}$ Lonicera japonica in the absence of a light source (without irradiation and dark conditions) was investigated. When $\mathrm{CH} 27$ cells were incubated with $0.1 \%$ DMSO or $100 \mu \mathrm{g} / \mathrm{ml}$ Lonicera japonica for $3 \mathrm{~h}$ in the dark, there were no differences in DCF fluorescence intensity between treated and control groups (data not shown).

\section{The phototoxicity of partitioned fractions of Lonicera japonica extracts}

The present study served to evaluate the potent photokilling fraction of ethanol extracts of Lonicera japonica. The alcoholic extracts of Lonicera japonica was suspended in water and successively partitioned with ethyl acetate and $n$-butanol. The photocytotoxicity of partitioned fractions (water, ethyl acetate and $n$-butanol) 


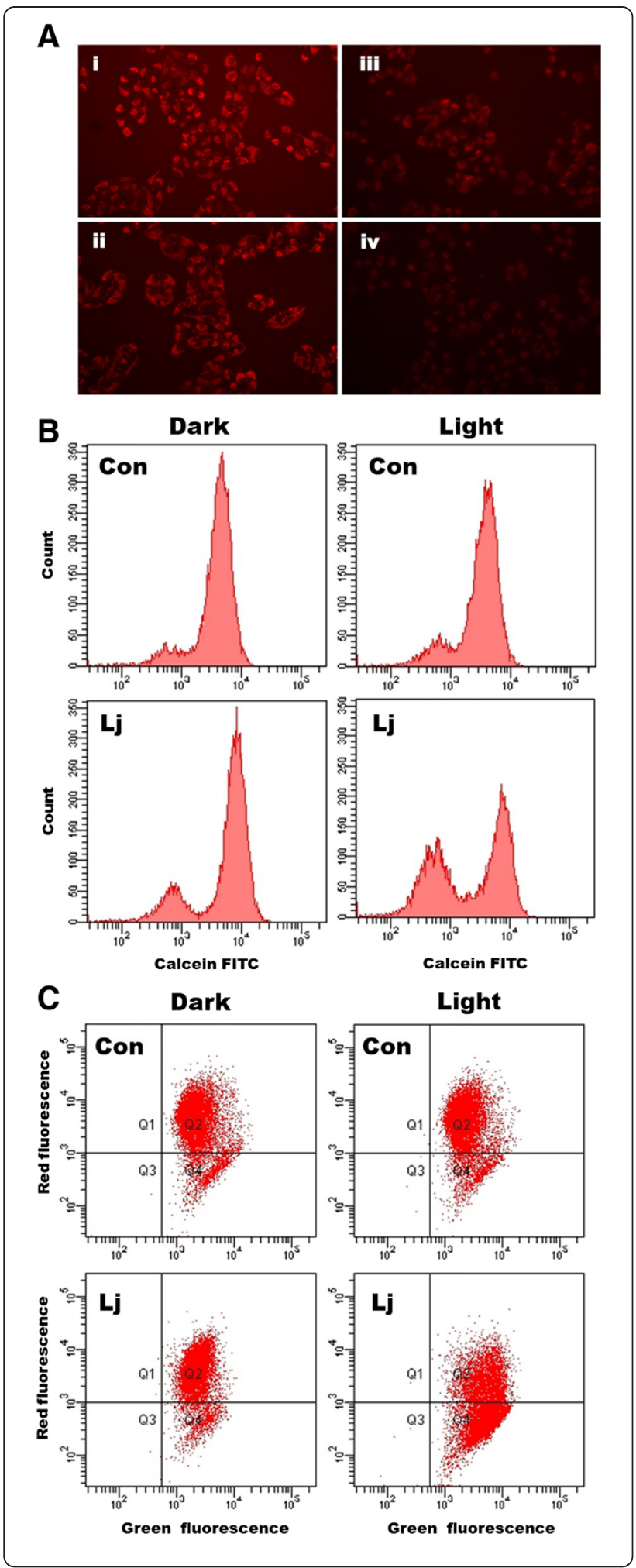

Figure 2 Effects of photoactivated Lonicera japonica extract on mitochondrial function in $\mathrm{CH} 27$ cells. (A) Effects of

photoactivated Lonicera japonica extracts on the activity of mitochondria in $\mathrm{CH} 27$ cells. $\mathrm{CH} 27$ cells were incubated with $0.1 \%$ DMSO (i) or with 50 (ii), 100 (iii) or 150 (iv) $\mu \mathrm{g} / \mathrm{ml}$ Lonicera japonica for $4 \mathrm{~h}$ and then irradiated with $0.8 \mathrm{~J} / \mathrm{cm}^{2}$ fluence dose. After treatment, cells were incubated with $100 \mathrm{nM}$ MitoTracker Red CMXRos for $30 \mathrm{~min}$. The specimens were observed by fluorescence microscopy (300X). (B) The effect of photoactivated Lonicera japonica extracts on opening of mitochondrial permeability transition (MPT) pore in $\mathrm{CH} 27$ cells. Cells were incubated with $0.1 \%$ DMSO (Con) or $100 \mu \mathrm{g} / \mathrm{mL}$ Lonicera japonica extracts (Lj) for $4 \mathrm{~h}$ and then irradiated with $0.8 \mathrm{~J} / \mathrm{cm}^{2}$ fluence dose. Before treatment with Lonicera japonica extracts and light, cells were loaded with $1 \mu \mathrm{M}$ calcein AM for 30 min in DMEM medium containing $1 \mathrm{mM} \mathrm{CoCl}_{2}$. After irradiation, the cells were harvested and then analyzed by flow cytometry for loss of fluorescence intensity due to efflux of the dye. In light-shield condition (dark), cells were incubated with $0.1 \%$ DMSO (Con) or $100 \mu \mathrm{g} / \mathrm{ml}$ Lonicera japonica extracts (Lj) for $5 \mathrm{~h}$. (C) The fluorescent cation dye JC-1 was used to determine the mitochondrial membrane potential. Cells were incubated with $0.1 \%$ DMSO (Con) or $100 \mu \mathrm{g} / \mathrm{mL}$ Lonicera japonica extracts (Lj) for $4 \mathrm{~h}$ and then irradiated with $0.8 \mathrm{~J} / \mathrm{cm}^{2}$ fluence dose. After irradiation, the cells were harvested and stained with $2 \mu \mathrm{M} \mathrm{JC}-1$ for $15 \mathrm{~min}$. The mitochondrial depolarization patterns of the $\mathrm{CH} 27$ cells were measured by flow cytometry. In light-shield condition (dark), cells were incubated with $0.1 \%$ DMSO (Con) or $100 \mu \mathrm{g} / \mathrm{ml}$ Lonicera japonica extracts (Lj) for $5 \mathrm{~h}$. All results are representative of three independent experiments.

of the Lonicera japonica extracts is shown in Figure 6. Results show that the ethyl acetate fraction of the Lonicera japonica extracts caused a significant photocytotoxicity in a dose-dependent manner in $\mathrm{CH} 27$ cells. The water and $n$-butanol fractions did not show any photokilling effect at $25 \mu \mathrm{g} / \mathrm{ml}$ and $0.8 \mathrm{~J} / \mathrm{cm}^{2}$ light dose (Figure 6).

\section{Discussion}

In the result of 2D gel electrophoresis, many protein spots were found varying in intensity between the control cell-loaded and the photoactivated Lonicera japonica-treated cell-loaded gels. These altered proteins were characterized by mass spectrometry. The identified proteins can be classified into three major groups, which include proteins involved in mitochondrial function (DJ-1, ATP synthase, heat shock protein 70 and chaperonin, also known as heat shock protein 60 ), proteins associated with ER stress (protein disulfide isomerase) and cytoskeleton-related proteins (heat shock protein 27, tropomyosin and actin cytoplasmic 1). In our previous study, cytoskeleton-related proteins, p38 signaling pathway, have been reported to be involved in photoactivated Lonicera japonica-induced $\mathrm{CH} 27$ cell apoptosis [3].

Since DJ-1, ATP synthase, HSP60 and HSP70 are mitochondrial protein, we hypothesized that photoactivated $L o$ nicera japonica induces $\mathrm{CH} 27$ cell apoptosis in association with regulation of mitochondrial function. The MPT pore 


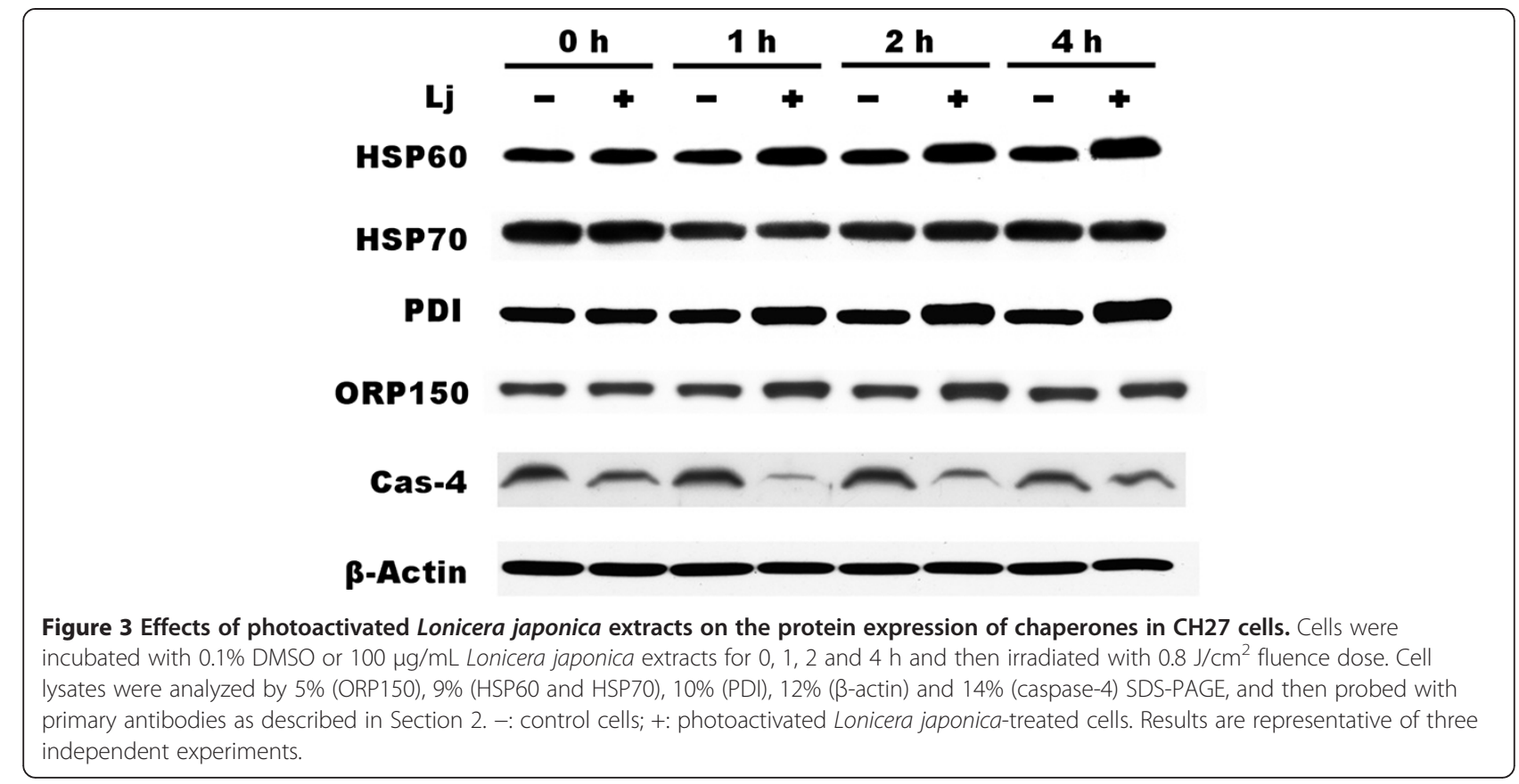

is characterized by opening of the permeability transition pore in the inner mitochondrial membrane, which results in an increase in permeability of this membrane to protons, ions and small-molecular weight solutes [18]. This increased permeability is also considered to lead to a collapse of the MMP $[19,20]$. We demonstrated that photoactivated Lonicera japonica induced the opening of MPT pores accompanied by a disruption of MMP in $\mathrm{CH} 27$ cells. In addition, photoactivated Lonicera japonica induced a significant reduction in the capability for MitoTracker Red
CMXRos uptake by mitochondria. These data suggested that mitochondria may be a target of photoactivated Lonicera japonica during photoactivated Lonicera japonicainduced $\mathrm{CH} 27$ cell death.

Molecular chaperones are major components of the cellular machinery involved in ensuring correct protein folding and the continued maintenance of protein structure. In this study, proteomic data showed that chaperones were involved in the photoactivated Lonicera japonica-induced $\mathrm{CH} 27$ cell apoptosis. DJ-1, HSP60 and
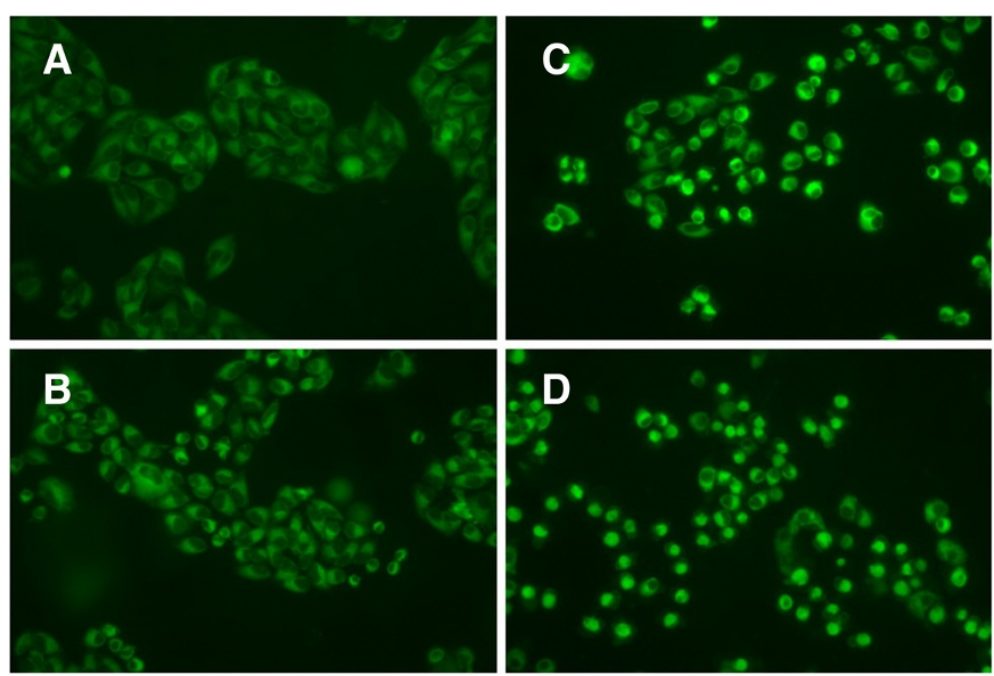

Figure 4 Effects of photoactivated Lonicera japonica on the distribution of endoplasmic reticulum in $\mathrm{CH} 27$ cells. $\mathrm{CH} 27$ cells were incubated with $0.1 \%$ DMSO (A) or with 50 (B), 100 (C) or 150 (D) $\mathrm{\mu g} / \mathrm{ml}$ Lonicera japonica for $4 \mathrm{~h}$ and then irradiated with $0.8 \mathrm{~J} / \mathrm{cm}^{2}$ fluence dose. After irradiation, cells were incubated with ER-Tracker and then examined by fluorescence microscopy (300x). Results are representative of three independent experiments. 


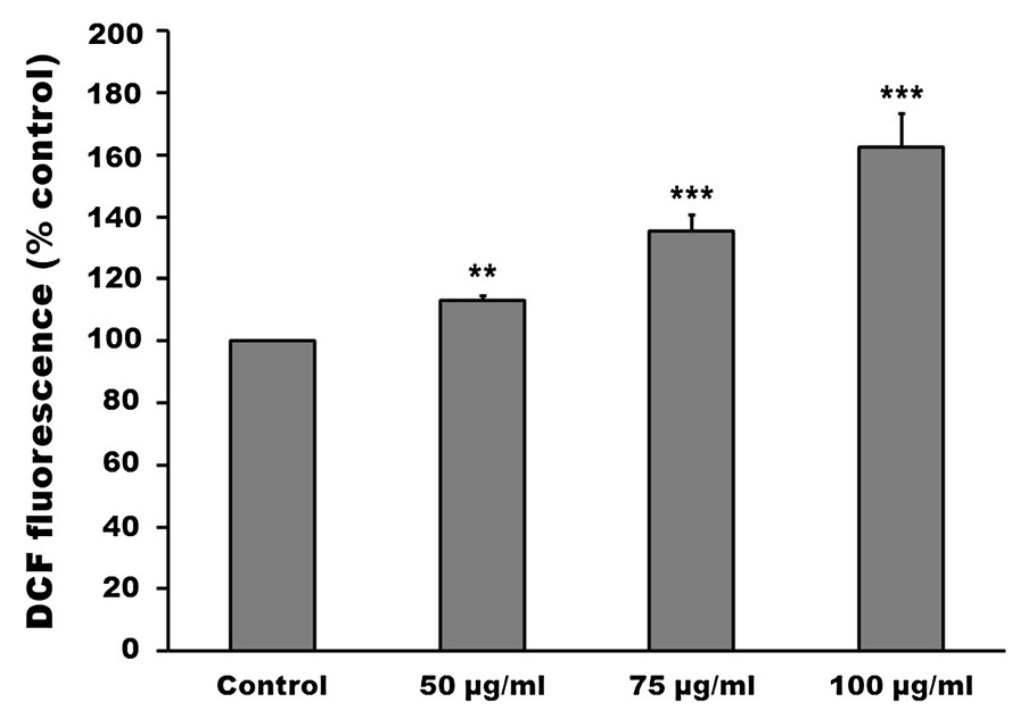

Figure 5 Effects of photoactivated Lonicera japonica on reactive oxygen species (ROS) production in CH27 cells. Cells were loaded with 5- $\mathrm{H}_{2}$ DCFDA $(5 \mu \mathrm{M})$ for $30 \mathrm{~min}$ in the dark, washed and then treated with $0.1 \%$ DMSO or with 50,75 or $100 \mu \mathrm{g} / \mathrm{ml}$ Lonicera japonica for $2 \mathrm{~h}$ and then irradiated with $0.8 \mathrm{~J} / \mathrm{cm}^{2}$ fluence dose. After irradiation, ROS fluorescence was measured using a multiwell plate reader at an excitation wavelength of $485 \mathrm{~nm}$ and an emission wavelength of $538 \mathrm{~nm}$. All results are expressed as the mean percentage of control \pm S.D. of triplicate determinations from four independent experiments. ${ }^{* *} P<0.01,{ }^{* * *} P<0.001$ compared to the corresponding control values.

HSP 70 are mitochondrial molecular chaperones. DJ-1 has been demonstrated to protect cells against oxidative stress and cell death [21]. Our results are also consistent with previous observations in which HSP60 and HSP70 play critical roles during apoptosis $[7,8]$. In the result of 2D gel electrophoresis, photoactivated Lonicera japonica-treated samples had a significant change in the expression of HSP70 protein (spot D4, \#3 and \#4). However, photoactivated Lonicera japonica had no effect on the protein expression of HSP70 by Western blotting analysis (Figure 3). HSP70 displays a spot family pattern in 2D gel. After cells were treated with Lonicera japonica extracts and irradiation, the protein amount of spot \#3 and \#4 significantly increased, but spot D4 decreased. In Western blotting data, the expression of HSP70 is the total HSP70 protein. Based on the above reasons, photoactivated Lonicera japonica-treated samples had a significant change in the expression of HSP70 protein in

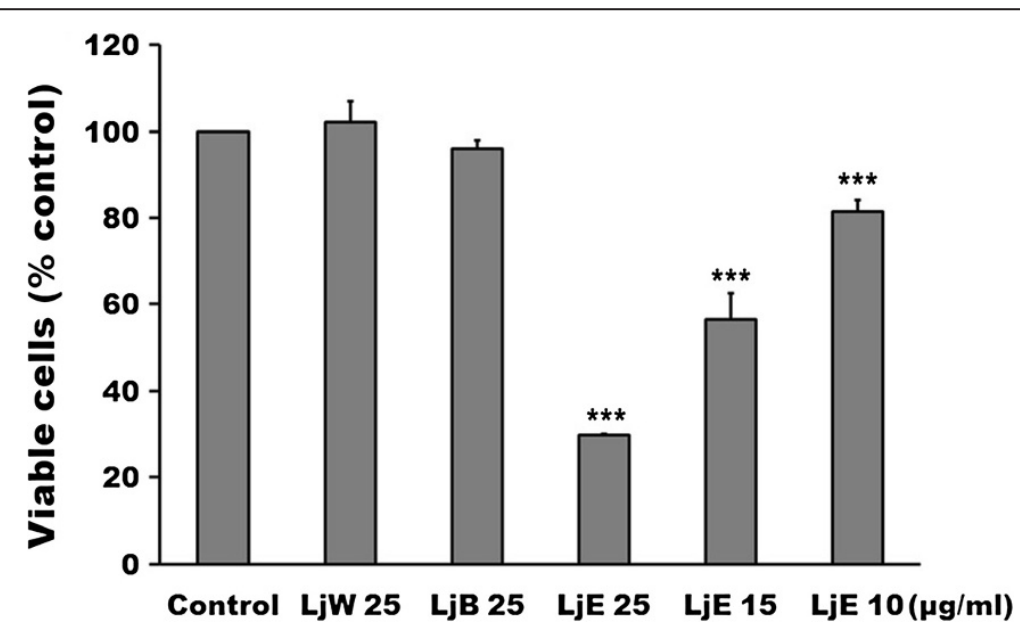

Figure 6 The photocytotoxicity of partitioned fractions of Lonicera japonica extracts of $\mathrm{CH} 27$ cells. Cells were incubated with various concentrations of ethyl acetate fraction of the Lonicera japonica extracts or with $25 \mu \mathrm{g} / \mathrm{ml}$ partitioned fractions of Lonicera japonica extracts for $4 \mathrm{~h}$ and then irradiated with $0.8 \mathrm{~J} / \mathrm{cm}^{2}$ fluence dose. The viable cells were measured by MTT assay. LjW: water fraction of the Lonicera japonica extracts; LjB: $n$-butanol fraction of the Lonicera japonica extracts; LjE: ethyl acetate fraction of the Lonicera japonica extracts. Results are expressed as the mean percentage of control \pm SD. ${ }^{* * *} P<0.001$ compared to the control values. 
which the single spots of the complex pattern were probably due to post-translational modifications of one particular protein.

In this study, proteomic data also showed that photoactivated Lonicera japonica induced the change of endoplasmic reticulum molecular chaperone protein disulfide isomerase (PDI), which catalyzes the rearrangement of -S-S- bonds in proteins. It has been suggested that a variety of endoplasmic reticulum stresses result from unfolded protein accumulation, which induces the expression of molecular chaperones [22]. Therefore, we focused our attention on molecular chaperone expression and ER stress. This study demonstrated that the molecular chaperones in the endoplasmic reticulum, such as PDI, caspase-4 and $150 \mathrm{kDa}$ oxygen-regulated protein (ORP150), are involved in photoactivated Lonicera japonica-induced $\mathrm{CH} 27$ cell apoptosis by increasing protein levels. It has been reported that caspase-4, an ER stress-specific caspase, is localized on the ER in human $[23,24]$. The $150 \mathrm{kDa}$ oxygen regulated protein functions as a molecular chaperone in the endoplasmic reticulum [25]. Photoactivated Lonicera japonica also induced the changes of endoplasmic reticulum distribution, which was performed by an endoplasmic reticulum marker, in $\mathrm{CH} 27$ cells in this study. These results are consistent with previous observations that have shown an association between cell death and the increase in the ER stress which can induce compensatory responses $[22,26]$. Based on the data mentioned above, ER stress and molecular chaperones expression may play an important role in the photoactivated Lonicera japonica-induced $\mathrm{CH} 27$ cell apoptosis. It also seemed to indicate that the protein folding pathway might serve as an important apoptotic control point in photoactivated Lonicera japonica-induced apoptosis.

When cells accumulate ER stresses, ER chaperone proteins can be induced to alleviate protein aggregation and activate the proteosome machinery to degrade misfolded proteins. For survival, the cells induce endoplasmic reticulum chaperone proteins to alleviate protein aggregation, transiently attenuate translation and activate the proteosome machinery to degrade misfolded proteins. In the results of $2 \mathrm{D}$ electrophoresis, most of protein spots are more intense in control cell-loaded gels than in the photoactivated Lonicera japonica-treated cell-loaded gels in this study. Furthermore, the present study has demonstrated that the molecular chaperones in the endoplasmic reticulum, such as PDI and ORP150, and mitochondria, such as HSP60 and HSP70, are involved in photoactivated Lonicera japonica-induced $\mathrm{CH} 27$ cell apoptosis. These results seemed to indicate that heat shock proteins were synthesized by $\mathrm{CH} 27$ cells in response to Lonicera japonica and irradiation and a compensatory mechanism referred to as unfolded protein response (UPR) was triggered by photoactivated Lonicera japonica. It includes the inhibition of overall protein synthesis to decrease the protein-load, as well as the induction of endoplasmic reticulum chaperones and foldases, by which the cell attempts to increase the folding capacity in this study.

It has been suggested that excessive production of reactive oxygen species (ROS) may lead to oxidative stress, loss of cell function and ultimately apoptosis in cancer cells [27]. Haynes et al. (2004) also reported that prolonged activation of UPR, which normally functions to prevent ROS accumulation, resulted in oxidative stress and consequent cellular death [28]. Furthermore, reactive oxygen species producing is believed to play a key role in photosensitizer-induced photocytotoxicity. Many investigators have suggested that PDT involves the activation of a photosensitizer by irradiation with light in the presence of oxygen to produce singlet oxygen and other reactive oxygen species which cause cancer cells undergoing apoptosis or necrosis [14-17]. During the photodynamic process, photosensitizer generates a variety of ROS including singlet molecular oxygen $\left({ }^{1} \mathrm{O}_{2}\right.$, produced via type II mechanism) and superoxide anions (type I mechanism) [29,30]. In this study, treatment with $100 \mu \mathrm{g} / \mathrm{ml}$ Lonicera japonica for $2 \mathrm{~h}$ and $0.8 \mathrm{~J} / \mathrm{cm}^{2}$ light dose resulted in significant increases in the intensity of the DCF signal as compared with those in the control. Therefore, the present study indicated that the production of ROS was involved in the photoactivated Lonicera japonica-induced $\mathrm{CH} 27$ cell death. Based on the above data, the study cannot verify that the amount of ROS was produced by photosensitizer Lonicera japonica via type I or type II mechanisms or induced by mitochondrial dysfunction and ER stress. However, the molecular chaperones should be triggered by photoactivated Lonicera japonica to counteract ROS accumulation during photoactivated Lonicera japonicainduced $\mathrm{CH} 27$ cell death.

\section{Conclusion}

Our study applied 2D electrophoresis to analyze the proteins involved in photoactivated Lonicera japonica-induced apoptosis in $\mathrm{CH} 27$ cells. Photoactivated Lonicera japonica induces significant changes in the protein expression of chaperones in mitochondria and endoplasmic reticulum. Endoplasmic reticulum and mitochondria are the targets of photoactivated Lonicera japonica during photoactivated Lonicera japonica-induced $\mathrm{CH} 27$ cell apoptosis. The production of reactive oxygen species was demonstrated to be involved in photoactivated Lonicera japonica-induced $\mathrm{CH} 27$ cell apoptosis. In a comparative study among various fractions of the Lonicera japonica extracts, such as water, ethyl acetate and $n$ butanol fractions, the results showed that the ethyl 
acetate fraction had the highest photosensitizing activity in this study. This could explain the fact that the ethyl acetate fraction of Lonicera japonica extracts may contain compounds that exhibit the photosensitizing activity in $\mathrm{CH} 27$ cells. However, further studies are required to isolate and characterize the constituents which displayed photosensitizing activity present in ethyl acetate fraction of Lonicera japonica extracts.

\section{Abbreviations}

BuOH: $n$-butanol; CHAPS: 3-[(3-cholamidopropyl)dimethylammonio]-1propanesulfonate; $\mathrm{CH} 27$ cells: Human lung squamous carcinoma cell line; CM-H 2 DCFDA: 5-(and-6)-chloromethyl-20,70-dichlorodihydrofluorescein diacetate; DMEM: Dulbecco's modified Eagle's medium; DMSO: Dimethylsulfoxide; DTT: Dithiothreitol; EGTA: Ethylene glycol bis(baminoethylether)-N,N,N',N'-tetraacetic acid; ER: Endoplasmic reticulum; EtOAc: Ethyl acetate; FBS: Fetal bovine serum; HSP: Heat shock protein; IEF: Isoelectric focusing; IgG: Immunoglobulin; JC-1: 5,5',6,6'-tetrachloro1,1',3,3'-tetraethylbenzimidazolocarbocyanine iodide; MAPKs: Mitogenactivated protein kinases; MMP: Mitochondrial membrane potential; MPT: Mitochondrial permeability transition; MTT: 3-(4,5-dimethylthiazol-2-yl)2,5-diphenyltetrazolium bromide; PAGE: Polyacrylamide gel electrophoresis; PBS: Phosphate-buffered saline; PDI: Protein disulfide isomerase; PDT: Photodynamic therapy; PMSF: Phenylmethylsulfonyl fluoride; ORP150: 150 kDa oxygen-regulated protein; ROS: Reactive oxygen species; SDS: Sodium dodecyl sulfate; UPR: Unfolded protein response.

\section{Competing interests}

The authors declare that they have no competing interests.

\section{Authors' contributions}

LHZ designed the study, conducted the experiments and wrote the manuscript. LHZ, LJC and CWT helped to wrote the manuscript. LHZ, LJC, CWT, LYH and HMJ performed the experiments and analyzed the data. LJC and CWT equally contributed to this work. All authors read and approved the final manuscript.

\section{Acknowledgements}

We thank Dr. Yi-Yu Wu for her critical reading of the manuscript and Ya-Win Yang for technical assistance. This work was supported by the China Medical University Grant CMU100-TS-03 and National Science Council Grant NSC 101-2320-B-039-055-MY2 of Republic of China.

\section{Author details}

${ }^{1}$ School of Pharmacy, China Medical University, Taichung, Taiwan. ${ }^{2}$ School of Chinese Pharmaceutical Sciences and Chinese Medicine Resources, China Medical University, Taichung, Taiwan.

Received: 1 July 2013 Accepted: 26 September 2013 Published: 1 October 2013

\section{References}

1. Park HS, Park KI, Lee DH, Kang SR, Nagappan A, Kim JA, Kim EH, Lee WS, Shin SC, Hah YS, Kim GS: Polyphenolic extract isolated from Korean Lonicera japonica Thunb. induce G2/M cell cycle arrest and apoptosis in HepG2 cells: involvements of PI3K/Akt and MAPKs. Food Chem Toxicol 2012, 50:2407-2416.

2. $X u$ Y, Oliverson BG, Simmons DL: Trifunctional inhibition of COX-2 by extracts of Lonicera japonica: direct inhibition, transcriptional and posttranscriptional down regulation. J Ethnopharmacol 2007, 111:667-670.

3. Leung HW, Hour MJ, Chang WT, Wu YC, Lai MY, Wang MY, Lee HZ: P38associated pathway involvement in apoptosis induced by photodynamic therapy with Lonicera japonica in human lung squamous carcinoma CH27 cells. Food Chem Toxicol 2008, 46:3389-3400.

4. You BJ, Wu YC, Bao BY, Wu CY, Yang YW, Chang YH, Lee HZ: Rottlerin Inhibits Lonicera japonica-Induced Photokilling in Human Lung Cancer Cells through Cytoskeleton-Related Signaling Cascade. Evid Based Complement Alternat Med 2011, 2011:193842.
5. Dallmann K, Junker H, Balabanov S, Zimmermann U, Giebel J, Walther R: Human agmatinase is diminished in the clear cell type of renal cell carcinoma. Int J Cancer 2004, 108:342-347.

6. van den Bogaerdt AJ, El Ghalbzouri A, Hensbergen PJ, Reijnen L, Verkerk M, Kroon-Smits M, Middelkoop E, Ulrich MMW: Differential expression of CRABP-II in fibroblasts derived from dermis and subcutaneous fat. Biochem Biophys Res Commun 2004, 315:428-433.

7. Lin KM, Lin B, Lian IY, Mestril R, Scheffler I, Dillmann WH: Combined and individual mitochondrial HSP60 and HSP10 expression in cardiac myocytes protects mitochondrial function and prevents apoptotic cell deaths induced by simulated ischemia-reoxygenation. Circulation 2001, 103:1787-1792.

8. Beere HM, Wolf BB, Cain K, Mosser DD, Mahboubi A, Kuwana T, Tailor P, Morimoto RI, Cohen GM, Green DR: Heat-shock protein 70 inhibits apoptosis by preventing recruitment of procaspase- 9 to the Apaf-1 apoptosome. Nat Cell Biol 2000, 2:469-475.

9. Garrido C, Bruey JM, Fromentin A, Hammann A, Arrigo AP, Solary E: HSP27 inhibits cytochrome c-dependent activation of procaspase-9. FASEB J 1999, 13:2061-2070.

10. Feng $R$, Zhai $W L$, Yang HY, Jin $H$, Zhang QX: Induction of ER stress protects gastric cancer cells against apoptosis induced by cisplatin and doxorubicin through activation of p38 MAPK. Biochem Biophys Res Commun 2011, 406:299-304.

11. Lee HZ, Liu WZ, Hsieh WT, Tang FY, Chung JG, Leung HW: Oxidative stress involvement in Physalis angulata-induced apoptosis in human oral cancer cells. Food Chem Toxicol 2009, 47:561-570.

12. Lindholm D, Wootz H, Korhonen L: ER stress and neurodegenerative diseases. Cell Death Differ 2006, 13:385-392

13. Lemarie A, Lagadic-Gossmann D, Morzadec C, Allain N, Fardel O, Vernhet L: Cadmium induces caspase-independent apoptosis in liver Hep3B cells: role for calcium in signaling oxidative stress-related impairment of mitochondria and relocation of endonuclease $\mathrm{G}$ and apoptosis-inducing factor. Free Radic Biol Med 2004, 36:1517-1531.

14. Chen R, Huang Z, Chen G, Li Y, Chen X, Chen J, Zeng H: Kinetics and subcellular localization of 5-ALA-induced PpIX in DHL cells via twophoton excitation fluorescence microscopy. Int J Oncol 2008, 32:861-867.

15. Donnelly RF, McCarron PA, Woolfson AD: Derivatives of 5-aminolevulinic acid for photodynamic therapy. Perspect Med Chem 2007, 1:49-63.

16. Fotinos N, Mikulic J, Convert M, Campo MA, Piffaretti JC, Gurny R, Lange N: 5-ALA derivative-mediated photoinactivation of Propionibacterium acnes. J Dermatol Sci 2009, 56:214-216.

17. Sharma S, Jajoo A, Dube A: 5-Aminolevulinic acid-induced protoporphyrin-IX accumulation and associated phototoxicity in macrophages and oral cancer cell lines. J Photochem Photobiol B 2007, 88:156-162

18. Zoratti M, Szabò I: The mitochondrial permeability transition. Biochim Biophys Acta 1995, 1241:139-176.

19. Crompton M: The mitochondrial permeability transition pore and its role in cell death. Biochem J 1999, 341:233-249.

20. Oliveira KA, Zecchin KG, Alberici LC, Castilho RF, Vercesi AE: Simvastatin inducing PC3 prostate cancer cell necrosis mediated by calcineurin and mitochondrial dysfunction. J Bioenerg Biomembr 2008, 40:307-314.

21. Takahashi-Niki K, Niki T, Iguchi-Ariga S, Ariga H: Function of DJ-1 in mitochondria. Yakugaku Zasshi 2012, 132:1105-1110.

22. Kudo T, Okumura M, Imaizumi K, Araki W, Morihara T, Tanimukai H, Kamagata E, Tabuchi N, Kimura R, Kanayama D, Fukumori A, Tagami S, Okochi M, Kubo M, Tanii H, Tohyama M, Tabira T, Takeda M: Altered localization of amyloid precursor protein under endoplasmic reticulum stress. Biochem Biophys Res Commun 2006, 344:525-530.

23. Hitomi J, Katayama T, Eguchi $Y$, Kudo T, Taniguchi M, Koyama $Y$, Manabe T, Yamagishi S, Bando Y, Imaizumi K, Tsujimoto Y, Tohyama M: Involvement of caspase-4 in endoplasmic reticulum stress-induced apoptosis and Abeta-induced cell death. J Cell Biol 2004, 165:347-356.

24. Li J, Xia X, Ke Y, Nie H, Smith MA, Zhu X: Trichosanthin induced apoptosis in HL-60 cells via mitochondrial and endoplasmic reticulum stress signaling pathways. Biochim Biophys Acta 2007, 1770:1169-1180.

25. Ikeda J, Kaneda S, Kuwabara K, Ogawa S, Kobayashi T, Matsumoto M, Yura T, Yanagi $\mathrm{H}$ : Cloning and expression of cDNA encoding the human $150 \mathrm{kDa}$ oxygen-regulated protein, ORP150. Biochem Biophys Res Commun 1997, 230:94-99. 
26. Lai MY, Hour MJ, Leung WC, Yang WH, Lee HZ: Chaperones are the target in aloe-emodin-induced human lung nonsmall carcinoma $\mathrm{H} 460$ cell apoptosis. Eur J Pharmacol 2007, 573:1-10.

27. Lau AT, Wang Y, Chiu JF: Reactive oxygen species: current knowledge and applications in cancer research and therapeutic. J Cell Biochem 2008, 104:657-667.

28. Haynes CM, Titus EA, Cooper AA: Degradation of misfolded proteins prevents ER-derived oxidative stress and cell death. Mol Cell 2004, 15:767-776.

29. Pass HI: Photodynamic therapy in oncology: Mechanisms and clinical use. J Natl Cancer Inst 1993, 85:443-456.

30. Vath P, Wamer WG, Falvey DE: Photochemistry and phototoxicity of aloe emodin. Photochem Photobiol 2002, 75:346-352.

doi:10.1186/1472-6882-13-244

Cite this article as: Liao et al:: Application of proteomics to identify the target molecules involved in Lonicera japonica-induced photokilling in human lung cancer $\mathrm{CH} 27$ cells. BMC Complementary and Alternative Medicine 2013 13:244.

\section{Submit your next manuscript to BioMed Central} and take full advantage of:

- Convenient online submission

- Thorough peer review

- No space constraints or color figure charges

- Immediate publication on acceptance

- Inclusion in PubMed, CAS, Scopus and Google Scholar

- Research which is freely available for redistribution 